\title{
Endovascular repair of an abdominal aortic aneurysm associated with ectopic kidney: A case report
}

\author{
Seyhan Yllmaz (D), Emre Demir Benli(D), İsa Çam (D), Cantürk Çakalağaoğlu (D), Mehmet Kalender (D), Feryaz Kızıltan (D) \\ Department of Cardiovascular Surgery, Çorlu State Hospital, Tekirdağ, Turkey
}

\begin{abstract}
Classical surgical repair of abdominal aortic aneurysms associated with kidney anomalies is described as a very difficult process due to abnormal vascular and excretory system anatomy, and endovascular aneurysm repair does not often seem to be an attractive treatment option in this patient population. Herein, we present a case of an abdominal aortic aneurysm associated with ectopic kidney which was successfully treated with endovascular aneurysm repair.
\end{abstract}

Keywords: Abdominal aortic aneurysm, ectopic kidney, endovascular procedures.

Classical surgical repair of abdominal aortic aneurysms (AAAs) associated with kidney anomalies is described as a difficult process due to abnormal vascular and excretory system anatomy, and endovascular aneurysm repair (EVAR) does not often seem to be an attractive treatment option for these patients. ${ }^{[1]}$ Therefore, some AAAs associated with renal anomalies can be treated with EVAR, considering the risk for the loss of some renal arteries. ${ }^{[1]}$

In this article, we present a case of AAA associated with ectopic kidney which was successfully treated with EVAR.

\section{CASE REPORT}

A 73-year-old male patient with a known AAA for five years was admitted to our outpatient clinic due to abdominal pain. His medical history revealed obesity and coronary artery disease with a smoking history. Computed tomography angiography (CTA) revealed an infrarenal fusiform AAA, 6-cm diameter in size, and an abnormal renal artery originating from just above the level of aortic bifurcation to a cross-fused ectopic kidney (Figure 1). Preoperative laboratory test results including urea and creatinine values were within the normal limits. A written informed consent was obtained from the patient and he was transferred to the angiography unit under local anesthesia. Successful AAA repair was performed with EVAR. In addition to fluid replacement, $\mathrm{N}$-acetylcysteine treatment was given. The patient needed no additional medication during the postoperative two days. No pathology was observed in the urine output and laboratory tests after the procedure. The patient was discharged on the postoperative day with medical treatment. Control imaging was performed with CTA at postoperative four months and repeated CTA revealed that the ectopic kidney had less contrast than the left kidney and the ectopic kidney was hypoplastic (Figure 2).

\section{DISCUSSION}

Currently, EVAR is a preferred method for anatomically suitable patients with AAAs, and the most important factor for the applicability of this technique is the relation of the renal arteries to the aneurysm incision. ${ }^{[2,3]}$ Ectopic kidney may increase the

Received: September 25, 2019 Accepted: January 08, 2020 Published online: March 10, 2020

Correspondence: Seyhan Yllmaz, MD. Çorlu Devlet Hastanesi Kalp ve Damar Cerrahisi Kliniği, 59850 Çorlu, Tekirdağ, Türkiye. e-mail: dr61@mail.com 


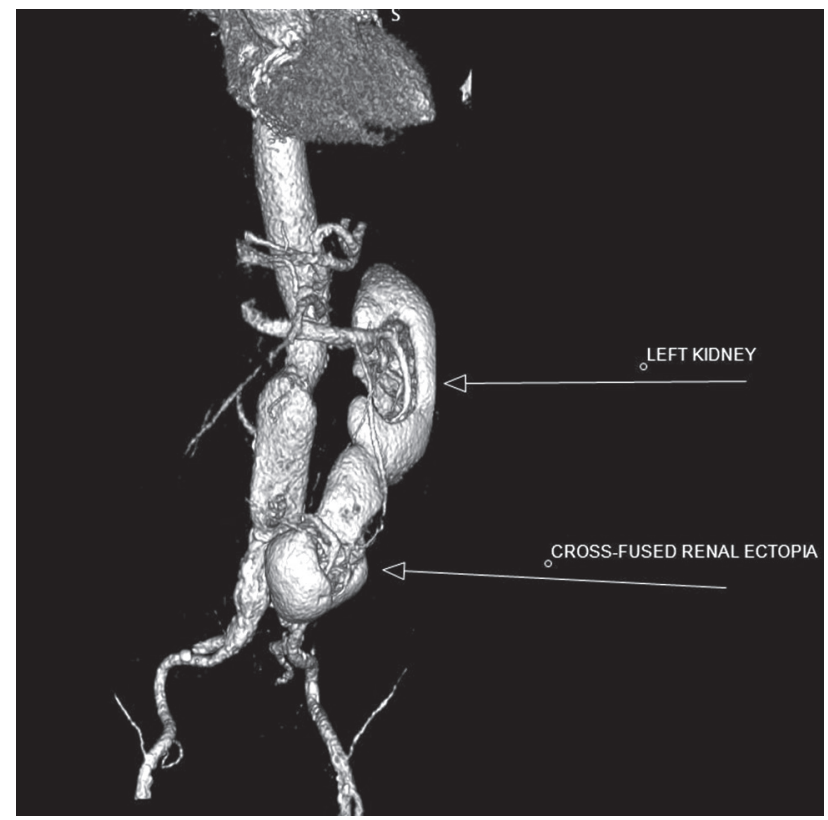

Figure 1. A preoperative computed tomography angiography image. Left kidney and cross-fused ectopic kidney.

complexity of EVAR due to the anatomy of aberrant renal arteries and there are some reports that occlusion of small accessory renal arteries during EVAR typically causes partial renal infarctions. ${ }^{[2-4]}$ In addition, Kaplan et al. ${ }^{[2]}$ reported that accessory renal arteries could be safely occluded, when the renal infarction was less than $20 \%$. Similarly, Carnicelli et al. ${ }^{[5]}$ reported a case of horseshoe kidney in whom an endograft was placed to the distal of the main renal arteries with iliorenal revascularization for large accessory renal arteries without causing complete renal ischemia. In our patient, considering the high risks for current classical AAA surgery, the endograft was placed, despite the risk for losing the cross-fused ectopic kidney, and control CTA at four months revealed that the ectopic kidney had less contrast than the left kidney and it was hypoplastic.

In another study, Antoniou et al. ${ }^{[6]}$ concluded that segmental renal infarction might occur in a significant portion of cases due to aberrant renal artery exclusion; however, it was not associated with adverse events, such as renal insufficiency or altered hypertensive status. Unlike this study, in our patient, there was no kidney failure which could would adversely affect the clinical status of the patient, or impair renal function tests or hypertensive status during the postoperative period.

In conclusion, in the association of AAAs with cross-fused ectopic kidney which is not a common

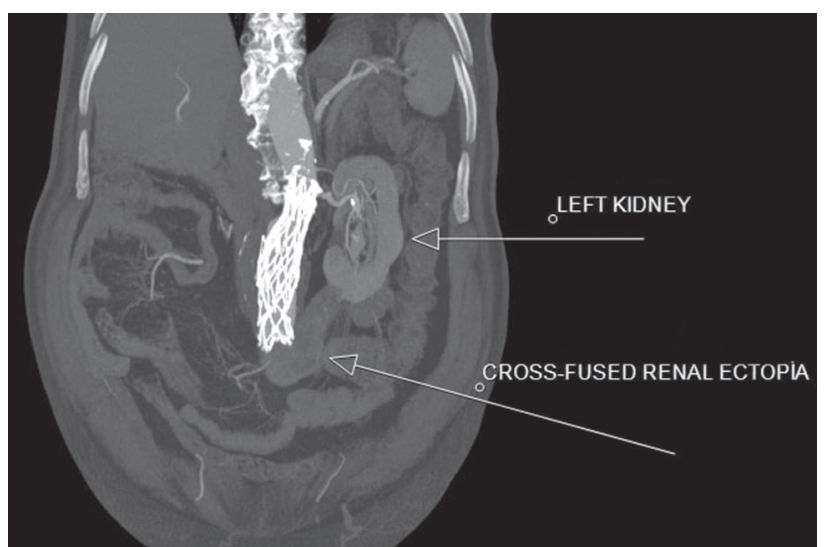

Figure 2. A postoperative computed tomography angiography image of the patient at four months. Left kidney and less contrasting - hypoplastic ectopic kidney.

condition, a separate solution should be sought for each patient considering the high risks for classical open surgery and the risk for EVAR leading to renal artery loss, and the risk-benefit ratio of the treatment options should be evaluated in detail. In this case, we had a successful AAA repair with EVAR, despite the risk for cross-fused ectopic kidney sacrifice due to the high mortality and morbidity rates of classical AAA surgery. In such patients, we believe that EVAR seems to be a safe and effective option with a high success rate and low risk.

\section{Declaration of conflicting interests}

The authors declared no conflicts of interest with respect to the authorship and/or publication of this article.

\section{Funding}

The authors received no financial support for the research and/or authorship of this article.

\section{REFERENCES}

1. Schneider JR, Patel NH, Kim S, Verta MJ. Preemptive coil occlusion of major aberrant renal artery to allow endovascular repair of abdominal aortic aneurysm with crossed fused renal ectopia. Ann Vasc Surg 2014;28:1318.e1-6.

2. Kaplan DB, Kwon CC, Marin ML, Hollier LH. Endovascular repair of abdominal aortic aneurysms in patients with congenital renal vascular anomalies. J Vasc Surg 1999;30:407-15.

3. Dorffner R, Thurnher S, Prokesch R, Youssefzadeh S, Hölzenbein T, Lammer J. Spiral CT during selective accessory renal artery angiography: assessment of vascular territory before aortic stent-grafting. Cardiovasc Intervent Radiol 1998;21:179-82. 
4. Murakami T, Makino Y, Suto Y, Yasuda K. Abdominal aortic aneurysm repair in a patient with a congenital solitary pelvic kidney. A case report. J Cardiovasc Surg 2004;45:501-4.

5. Carnicelli AP, Doyle A, Singh M. Hybrid repair of an abdominal aortic aneurysm in a patient with a horseshoe kidney. J Vasc Surg 2013;57:1113-5.

6. Antoniou GA, Karkos CD, Antoniou SA, Georgiadis GS. Can an accessory renal artery be safely covered during endovascular aortic aneurysm repair? Interact Cardiovasc Thorac Surg 2013;17:1025-7. 